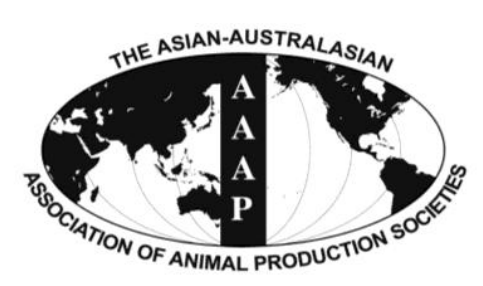

Open Access

Asian Australas. J. Anim. Sci.

Vol. 28, No. 3 : 420-427 March 2015

http://dx.doi.org/10.5713/ajas.14.0761

www.ajas.info

pISSN 1011-2367 elSSN 1976-5517

\title{
Cellular Uptake and Cytotoxicity of $\beta$-Lactoglobulin Nanoparticles: The Effects of Particle Size and Surface Charge
}

\author{
Ho-Kyung Ha, Jin Wook Kim, Mee-Ryung Lee ${ }^{1}$, Woojin Jun $^{2}$, and Won-Jae Lee* \\ Department of Animal Bioscience (Institute of Agriculture and Life Science), \\ Gyeongsang National University, Jinju 660-701, Korea
}

\begin{abstract}
It is necessary to understand the cellular uptake and cytotoxicity of food-grade delivery systems, such as $\beta$-lactoglobulin $(\beta-\lg )$ nanoparticles, for the application of bioactive compounds to functional foods. The objectives of this study were to investigate the relationships between the physicochemical properties of $\beta$-lg nanoparticles, such as particle size and zeta-potential value, and their cellular uptakes and cytotoxicity in Caco- 2 cells. Physicochemical properties of $\beta$-lg nanoparticles were evaluated using particle size analyzer. Flow cytometry and confocal laser scanning microscopy were used to investigate cellular uptake and cytotoxicity of $\beta$-lg nanoparticles. The $\beta$-lg nanoparticles with various particle sizes $(98$ to $192 \mathrm{~nm})$ and zeta-potential values $(-14.8$ to $-17.6 \mathrm{mV})$ were successfully formed. A decrease in heating temperature from $70^{\circ} \mathrm{C}$ to $60^{\circ} \mathrm{C}$ resulted in a decrease in the particle size and an increase in the zeta-potential value of $\beta$-lg nanoparticles. Non-cytotoxicity was observed in Caco- 2 cells treated with $\beta$-lg nanoparticles. There was an increase in cellular uptake of $\beta$-lg nanoparticles with a decrease in particle size and an increase in zeta-potential value. Cellular uptake $\beta$-lg nanoparticles was negatively correlated with particle size and positively correlated with zeta-potential value. Therefore, these results suggest that the particle size and zeta-potential value of $\beta$-lg nanoparticles play an important role in the cellular uptake. The $\beta$-lg nanoparticles can be used as a delivery system in foods due to its high cellular uptake and non-cytotoxicity. (Key Words: $\beta$ Lactoglobulin, Nanoparticle, Particle Size, Zeta-potential, Cellular Uptake, Cytotoxicity)
\end{abstract}

\section{INTRODUCTION}

Bioactive compounds, such as plant polyphenols and carotenoids, have been used in functional foods providing many health benefits since they may enhance antioxidant, anticancer, and antiviral activities and decrease the risks of diseases (Chen and Subirade, 2005; Chen et al., 2006; Hu et al., 2012). However, these bioactive compounds often have poor bioavailability due to their low aqueous solubility, low permeability across the intestinal cells, and low stability during food processing and storage (Chen and Subirade, 2005; Chen et al., 2006; Hu et al., 2012). To overcome these

\footnotetext{
* Corresponding Author: Won-Jae Lee. Tel: +82-55-772-1884, Fax: +82-55-772-1889, E-mail: wjleewisc@gnu.ac.kr

1 Department of Food and Nutrition, Daegu University, Gyeongsan 712-714, Korea.

${ }^{2}$ Division of Food and Nutrition, Chonnam National University, Gwangju 550-757, Korea.

Submitted Sept. 30, 2014; Revised Nov. 16, 2014; Accepted Nov. 20, 2014
}

problems, various delivery systems have been developed to entrap, protect, and deliver bioactive compounds to small intestine enhancing the bioavailability of compounds (Chen and Subirade, 2005; Chen et al., 2006; Zimet and Livney, 2009; Kumari and Yadav, 2011). Although many delivery systems have been successfully made using synthetic polymers, the production of synthetic polymer-based delivery systems may need the use of organic solvent and relatively hasher formulation condition. Therefore, foodgrade materials should be used for the manufacture of delivery systems for food applications (Chen and Subirade, 2005; Chen et al., 2006). In this study, beta-lactoglobulin $(\beta-\lg )$, the major component of whey proteins, was selected as a food-grade delivery material. The $\beta$-lg has great potentials for the preparation of delivery systems, which is applicable to foods due to its generally regarded as safe status, high nutritional level, biodegradable nature and gel forming capability (Chen and subirade, 2005; Livney, 2010).

In our previous study, modulating manufacturing

Copyright @ 2015 by Asian-Australasian Journal of Animal Sciences This is an open-access article distributed under the terms of the Creative Commons Attribution Non-Commercial License (http://creativecommons.org/licenses/by-nc/3.0/), which permits unrestricted non-commercial use, distribution, and reproduction in any medium, provided the original work is properly cited. 
variables including heat treatment resulted in the formation of whey protein nano delivery systems with various sizes and surface charges (Lee et al., 2008; Ha et al., 2013; Lee et al., 2013). It is known that reducing the particle size of delivery systems may enhance the bioavailability of bioactive compounds due to an increase in gastrointestinal transit time, adhesion to and interaction with biological cells, and cellular uptake of delivery systems (Win and Feng, 2005; Zhang et al., 2008; Iversen et al., 2011; Kumari and Yadav, 2011). Moreover, a decrease in the particle size from macroscopic scale to nanoscopic leads to changes in physico-chemical properties of the delivery materials and thus particles with smaller size may elicit different biological responses including toxicity (Yin et al., 2005; Napierska et al., 2009; Powell et al., 2010). On the other hand, the surface charge of nanoparticles can be considered as an important factor to affect the cellular uptake of nanoparticles because of the electrostatic interactions between the surface of nanoparticles and charged cell surface (Mansouri et al., 2006; Cho et al., 2009; Verma and Stellacci, 2010). Although the cellular uptake and cytotoxicity of several food-grade nanoparticles, such as chitosan-based (Zhang et al., 2008) and chitosancaseinophosphopeptide (Hu et al., 2012) nanoparticles has been examined, there is a lack of knowledge on the delivery of food-grade nanoparticles, especially $\beta$-lg nanoparticles, to intestinal cells and cytotoxicity. Therefore, more studies on the cellular uptake and cytotoxicity of $\beta-\lg$ nanoparticles are needed to apply $\beta$-lg nanoparticles with bioactive compounds to functional foods. In this study, we hypothesize that the particle size and surface charges of $\beta$-lg nanoparticles modulated by heat treatments can be a major factor to affect their cellular uptakes in Caco- 2 cells.

The objectives of this study were to manufacture $\beta$-lg nanoparticles with various sizes and surface charges by changing heating temperature, to determine the relationships between the particle size and surface charge of $\beta$-lg nanoparticles and their cellular uptakes in Caco-2 cells, and to evaluate the cytotoxicity of $\beta$-lg nanoparticles.

\section{MATERIALS AND METHODS}

\section{Chemicals and reagents}

The $\beta$-lg was generously supplied by Davisco International, Inc. (Le Sueur, MN, USA). Calcium chloride $\left(\mathrm{CaCl}_{2}\right)$, fluorescein isothiocyanate (FITC), and propidium iodide (PI) were purchased from Sigma-Aldirich Inc. (St. Louis, MO, USA). Sodium hydroxide $(\mathrm{NaOH})$ was purchased from Yakuri Pure Chemicals Co. (Osaka, Japan).

\section{Preparation of fluorescein isothiocynate-conjugated} beta-lactoglobulin nanoparticles

The FITC-conjugated $\beta$-lg nanoparticles were manufactured by the internal gelation method of Ha et al. (2013) and $\mathrm{Hu}$ et al. (2012). The $\beta$-lg solutions (1\%, w/v) were treated with $4 \mathrm{mM} \mathrm{CaCl}_{2}$ and adjusted to $\mathrm{pH} 9.5$ using $0.1 \mathrm{M} \mathrm{NaOH}$. To investigate the cellular uptake of $\beta-\mathrm{lg}$ nanoparticles, FITC, a fluorescent marker, was used (Hu et al., 2012). To manufacture FITC-conjugated $\beta-\lg , 0.1 \mathrm{~mL}$ of FITC solution $(40 \mathrm{mg} / \mathrm{mL}$ in ethanol) was added to $10 \mathrm{~mL}$ of $\beta$-lg solution in $0.1 \mathrm{M}$ carbonate buffer at $\mathrm{pH} 9.0$ and then FITC $/ \beta$-lg mixtures reacted for $2 \mathrm{~h}$ in a dark room. To remove unreacted FITC, FITC $/ \beta$-lg mixtures were dialyzed against distilled water for $48 \mathrm{~h}$ using a dialysis membrane (3.5 kDa molecular weight cut-off, Thermo Scientific, Rockford, USA) in a dark room. Those dialyzed mixtures were freeze dried to from FITC-conjugated $\beta$-lg. To manufacture FITC-conjugated $\beta$-lg nanoparticles, $1 \%(\mathrm{w} / \mathrm{v})$ FITC-conjugated $\beta$-lg solutions were treated with $4 \mathrm{mM}$ $\mathrm{CaCl}_{2}$ and adjusted to $\mathrm{pH} 9.5$ using $0.1 \mathrm{M} \mathrm{NaOH}$. The FITC-conjugated $\beta$-lg solutions were heated at $60^{\circ} \mathrm{C}, 65^{\circ} \mathrm{C}$, or $70^{\circ} \mathrm{C}$ for $10 \mathrm{~min}$ using a water bath (Wisecircu, Daihan Scientific, Inc., Seoul, Korea) and then cooled to room temperature in ice water.

\section{Particle size and zeta-potential measurements}

The particle size (mean particle diameter, Z-average) and zeta-potential value of $\beta$-lg nanoparticles were assessed by the use of Zetasizer Nano ZS (Malvern Instruments, UK). Nanoparticles were diluted (1:10) with deionized water prior to analysis. The particle size and zeta-potential value of nanoparticles were measured at room temperature with scattering angles of $90^{\circ}$ and $20^{\circ}$, respectively.

\section{Cell culture condition}

Caco-2 cells, which are human epithelial colorectal adenocarcinoma cells, were used as in vitro model to investigate the cellular uptake and cytotoxicity of $\beta-\mathrm{lg}$ nanoparticles. Caco-2 cells (ATCC HTB37) were obtained from American Type Culture Collection (ATCC, Manassas, VA, USA). Caco-2 cells were cultured in Dulbecco-Vogt modified Eagle medium (DMEM, Lonza BioWhittaker, Walkersvile, MD, USA) including $20 \%$ fetal bovine serum and $1 \%$ penicillin-streptomycin and maintained in $5 \% \mathrm{CO}_{2}$ incubator at $37^{\circ} \mathrm{C}$.

\section{Cytotoxicity and cellular uptake of beta-lactoglobulin nanoparticles: Quantitative studies}

Caco-2 cells were seeded in 6-well plates and incubated at $37^{\circ} \mathrm{C}, 5 \% \mathrm{CO}_{2}$ in $\mathrm{CO}_{2}$ incubator for $24 \mathrm{~h}$ to form a confluent monolayer. Culture medium was replaced by serum-free DMEM and incubated at $37^{\circ} \mathrm{C}$ for $30 \mathrm{~min}$. FITC-conjugated $\beta$-lg nanoparticles dissolved in serum-free DMEM were added to Caco- 2 cells and then incubated at $37^{\circ} \mathrm{C}$ for $0.5,1,2,3$, or $4 \mathrm{~h}$ to initiate the cellular uptake of nanoparticles. Final concentration of $\beta$ - $\lg$ nanoparticles in 
serum-free DMEM was 100,250 , or $500 \mu \mathrm{g} / \mathrm{mL}$. To remove free nanoparticles in serum-free DMEM, cells were washed three times with phosphate-buffered saline (PBS, pH 7.4) and collected with trypsin treatment. The FITC-conjugated $\beta$-lg nanoparticles were used as a marker to quantify the cellular uptake of $\beta$-lg nanoparticles. Cytotoxicity and cellular uptake of nanoparticles were evaluated by FACSCalibur flow cytometry and CellQuest Pro software (Becton Dickenson, Mississauga, CA, USA). In nanoparticle treated cells, cell viability was evaluated with PI staining followed by flow cytometric analysis (Russell et al., 2004; Chen et al., 2009). Excitation and emission wavelengths were $488 \mathrm{~nm}$ and $590 \mathrm{~nm}$, respectively. The percentage of live and dead cells was determined by measuring the PI-negative cells and PI-positive cells, respectively. The cell survival ratio was expressed as percent of PI-negative cells per control cells which were cultured in nanoparticle-free medium. The cellular uptake of FITC-conjugated $\beta$-lg nanoparticles in Caco- 2 cells was also analyzed using flow cytometry at $488 \mathrm{~nm}$ excitation wavelength and $530 \mathrm{~nm}$ emission wavelength (Pushpanathan et al., 2012). The FITC-positive cells indicate the number of Caco-2 cells that have uptaken $\beta$-lg nanoparticles. Cellular uptake efficiency was expressed as percent of FITC-positive cells per total cells.

Cellular uptake of beta-lactoglobulin nanoparticles: Qualitative studies

Confocal laser scanning microscopy (CLSM) was used to observe the cellular uptake of FITC-conjugated $\beta$-lg nanoparticle in Caco- 2 cells. To observe Caco- 2 cells, cells were grown on a glass microscope cover-slip. The nuclei of Caco- 2 cells were stained with PI $(0.1 \mathrm{mg} / \mathrm{mL})$. Cover-slips were then inverted and mounted onto microscope slides and cellular uptake of nanoparticles were observed using a CLSM (FV1000, Olympus, Tokyo, Japan) equipped with a $\times 40$ (numerical aperture, 1.0) oil immersion lens. Fluorescent images were analyzed using a confocal microscopy (Fluoview FV1000, Olympus, Tokyo, Japan). Fluorescence signals were detected at excitation/emission wavelengths of 535/617 nm (PI, red) and 488/530 nm (FITC, green), respectively.

\section{Statistical analysis}

All data were expressed as mean \pm standard errors. The significance of the effects of FITC conjugation, heating temperature, and their interaction was analyzed by a twoway analysis of variance (ANOVA). One-way ANOVA with the Fisher's least significant difference (LSD) test was used to analyze the effects of heating temperature on the zetapotential value, cytotoxicity, and cellular uptake of $\beta$-lg nanoparticles. Pearson's correlation coefficient analysis was used to determine the relationships between dependent

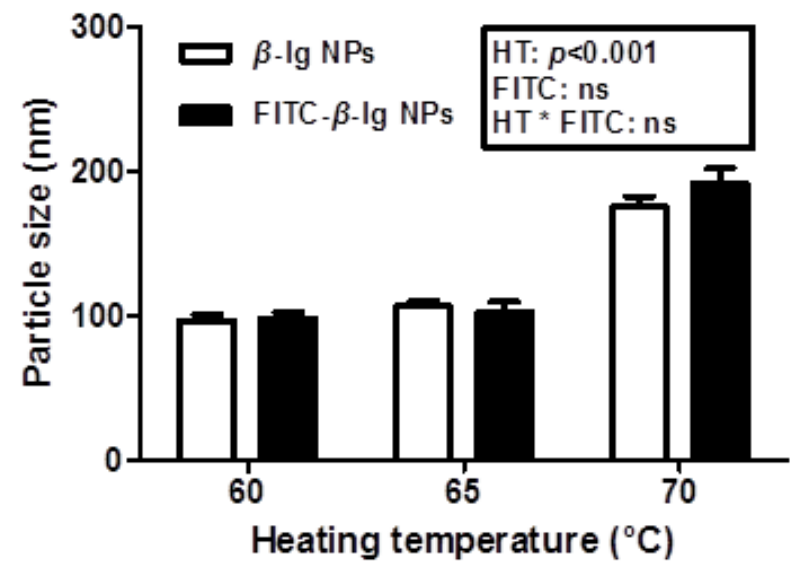

Figure 1. Particle size of $\beta$-lactoglobulin $(\beta-\lg )$ and fluorescein isothiocyanate-conjugated $\beta$-lg nanoparticles prepared at various heating temperature $\left(60^{\circ} \mathrm{C}, 65^{\circ} \mathrm{C}\right.$, and $\left.70^{\circ} \mathrm{C}\right)$. NPs, nanoparticles; $\mathrm{HT}$, heating temperature; ns, not significant $(\mathrm{p}>0.05)$.

variables (heating temperature, particle size, and zetapotential of $\beta-\lg$ nanoparticles). The level of significance was set at the $5 \%$ level $(\mathrm{p}<0.05)$. All statistical analyses were used with SAS software package (2003).

\section{RESULTS AND DISCUSSION}

Physicochemical properties of fluorescein isothiocyanateconjugated beta-lactoglobulin nanoparticles

Effects of heating temperature on the physicochemical properties of $\beta$-lg nanoparticles, such as particle size and zeta-potential, were shown in Figures 1 and 2. An increase in heating temperature from $60^{\circ} \mathrm{C}$ to $70^{\circ} \mathrm{C}$ resulted in a significant $(\mathrm{p}<0.05)$ increase in the size of $\beta$-lg nanoparticles from 97 to $176 \mathrm{~nm}$ (Figure 1). It was reported that the heat treatment of $\beta-\lg$ from $60^{\circ} \mathrm{C}$ to $70^{\circ} \mathrm{C}$ may lead to increased surface hydrophobicity and free sulfhydryl groups exposed to aqueous environment determined by

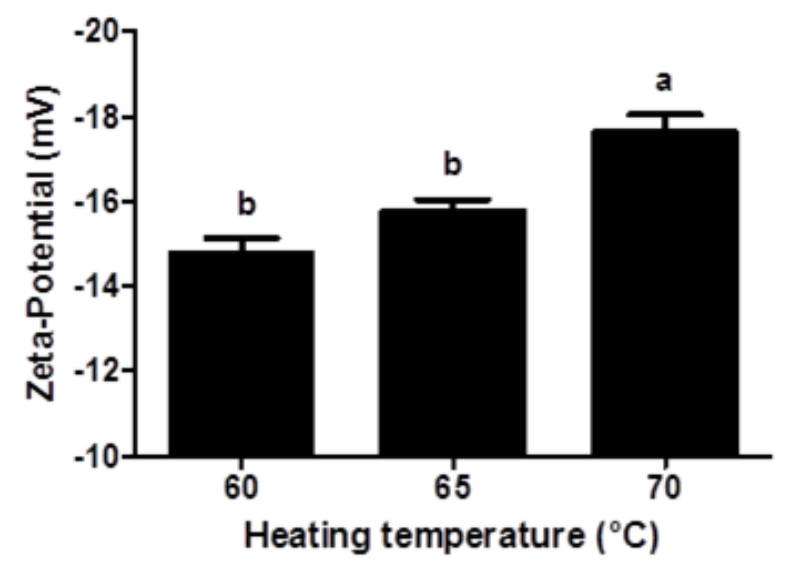

Figure 2. Zeta-potential of fluorescein isothiocyanate-conjugated $\beta$-lactoglobulin nanoparticles prepared at various heating temperature $\left(60^{\circ} \mathrm{C}, 65^{\circ} \mathrm{C}\right.$, and $\left.70^{\circ} \mathrm{C}\right)$. Different letters on a column indicate significant differences $(\mathrm{p}<0.05)$. 
ANS probe method and DTNB method, respectively (Lee et al., 2008; Lee et al., 2013). An increase in surface hydrophobicity and exposed free sulfhydryl residues can be a driving force to increase intermolecular hydrophobic attractions and thiol-disulfide interactions, which may lead an increase in the size of $\beta$-lg nanoparticles. Similar results were reported that the size of whey protein particles was increased from 70 to $200 \mathrm{~nm}$ as heating temperature was increased from $58^{\circ} \mathrm{C}$ to $77^{\circ} \mathrm{C}$ (Gracia-Julia et al., 2008). Conjugation of FITC with $\beta$-lg did not significantly $(\mathrm{p}<0.05)$ affect the size of nanoparticles (Figure 1).

Negative zeta-potential values $(-14.8$ to $-17.6 \mathrm{mV})$ were observed in $\beta$-lg nanoparticles, which indicates that $\beta$ $\lg$ nanoparticle had negative surface charges. Since the isoelectric point of $\beta$ - $\lg$ is about $5.3, \beta-\lg$ nanoparticles manufactured at $\mathrm{pH} 9.5$ had negative surface charges. Zetapotential value of $\beta$-lg nanoparticles was significantly $(\mathrm{p}<0.05)$ decreased from -14.8 to $-17.6 \mathrm{mV}$ when heating temperature was increased from $60^{\circ} \mathrm{C}$ to $70^{\circ} \mathrm{C}$ (Figure 2). An increase in heating temperature may lead to partial unfolding of $\beta$-lg. And thus, negatively charged amino acids buried inside of $\beta$-lg could be exposed to the surface of $\beta-\lg$, which could result in a decrease in the zeta-potential value of $\beta$-lg nanoparticles. Similar results were observed for $\beta$-lg dispersions heated at $85^{\circ} \mathrm{C}$ for $10 \mathrm{~min}$ (Schmitt et al., 2009).

\section{Cytotoxicity of beta-lactoglobulin nanoparticles}

There were growing interests in the safety and toxicity of nanoparticles since the small size of nanoparticles may cause toxicity problem (Yin et al., 2005; Napierska et al., 2009). A reduction in the size of nanoparticle led to an increase in the surface area, which can enhance interactions between nanoparticles and cell membranes (Zhang et al., 2008). Interactions between charged nanoparticles and cell membranes may induce the transient poration of cell membranes, which can be related to the cytotoxicity (Cockburn et al., 2012). The cytotoxicity of $\beta$-lg nanoparticles in Caco-2 cells were determined by measuring the cell survival ratio using flow cytometry prior to cellular uptake study (Figure 3). The measurement of cell survival ratio is the common method to investigate the in vitro cytotoxicity of biomaterials ( $\mathrm{Hu}$ et al., 2012). Nanoparticle concentration (100 to $500 \mu \mathrm{g} / \mathrm{mL}$ ) and incubation time $(0.5$ to $4 \mathrm{~h})$ did not significantly $(\mathrm{p}<0.05)$ affect the cell survival ratio. When Caco-2 cells were treated with FITC-conjugated $\beta$-lg nanoparticles at concentration of $250 \mu \mathrm{g} / \mathrm{mL}$ for $2 \mathrm{~h}$, no significant differences in cell survival ratio were observed indicating that $\beta$-lg nanoparticles had no cytotoxicity to Caco- 2 cells (Figure 3). Although $\beta$-lg nanoparticles had very small size ranging from 98 to $192 \mathrm{~nm}$, the size of $\beta$ - $\lg$ nanoparticles was not an important determinant in cytotoxicity. Similar results were reported for food-grade nanoparticles. Zhang et

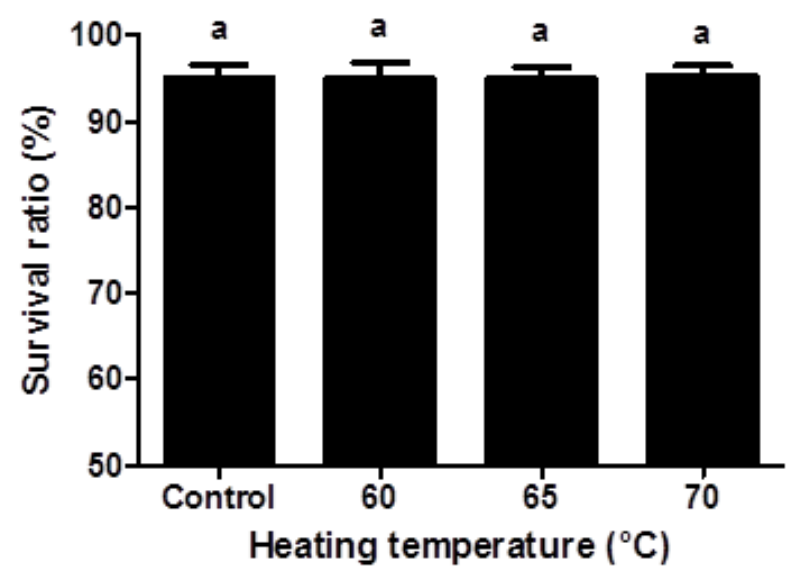

Figure 3. Viability of Caco- 2 cells treated with $\beta$-lactoglobulin ( $\beta$ $\lg )$ nanoparticles prepared at various heating temperature $\left(60^{\circ} \mathrm{C}\right.$, $65^{\circ} \mathrm{C}$, and $\left.70^{\circ} \mathrm{C}\right)$. The $\beta$-lg nanoparticles $(250 \mu \mathrm{g} / \mathrm{mL})$ were added to Caco- 2 cells and incubated at $37^{\circ} \mathrm{C}$ for $2 \mathrm{~h}$. Different letters on a column indicate significant differences $(\mathrm{p}<0.05)$.

al. (2008) reported that oleyl-chitosan nanoparticles exhibited no cytotoxicity when nanoparticles were treated with concentration up to $400 \mu \mathrm{g} / \mathrm{mL}$ on A549 cells. Chitosan-caseinophosphopeptide nanoparticles with concentration below $500 \mu \mathrm{g} / \mathrm{mL}$ were also non-toxic to Caco-2 cells (Hu et al., 2012).

\section{Cellular uptake of beta-lactoglobulin nanoparticles: Quantitative studies}

The in vitro or in vivo cellular uptake of nanoparticles was investigated by the use of fluorescent-based method (Win and Feng, 2005). In this study, Caco-2 cells were selected as in vitro model to investigate the cellular uptake of $\beta-\mathrm{lg}$ nanoparticles in small intestine since there are similar morphological and functional properties between Caco- 2 cell lines and small intestinal enterocytes (Win and Feng, 2005; Powell et al., 2010). Fluorescein isothiocynate, was used as a fluorescent marker to determine the cellular uptake of $\beta$-lg nanoparticles in Caco- 2 cells ( $\mathrm{Hu}$ et al., 2012). Since the concentration and incubation time of nanoparticle could be key factors to affect the in vitro cellular uptake of nanoparticles (Zhang et al., 2008), the effects of concentration and incubation time of nanoparticles on the cellular uptake of $\beta$ - $\lg$ nanoparticles were examined (Figure 4). As the concentration of $\beta-1 \mathrm{~g}$ nanoparticles was increased from 100 to $250 \mu \mathrm{g} / \mathrm{mL}$, the cellular uptake of $\beta$-lg nanoparticles was significantly $(\mathrm{p}<0.05)$ increased (Figure 4A). However, a further increase in the concentration of nanoparticles from 250 to 500 $\mu \mathrm{g} / \mathrm{mL}$ did not significantly $(\mathrm{p}<0.05)$ affect the cellular uptake of nanoparticles indicating that a saturation limit of nanoparticle was $250 \mu \mathrm{g} / \mathrm{mL}$. An increase in incubation time from 0.5 to $2 \mathrm{~h}$ resulted in a significant $(\mathrm{p}<0.05)$ increase in the cellular uptake of $\beta$-lg nanoparticles while 


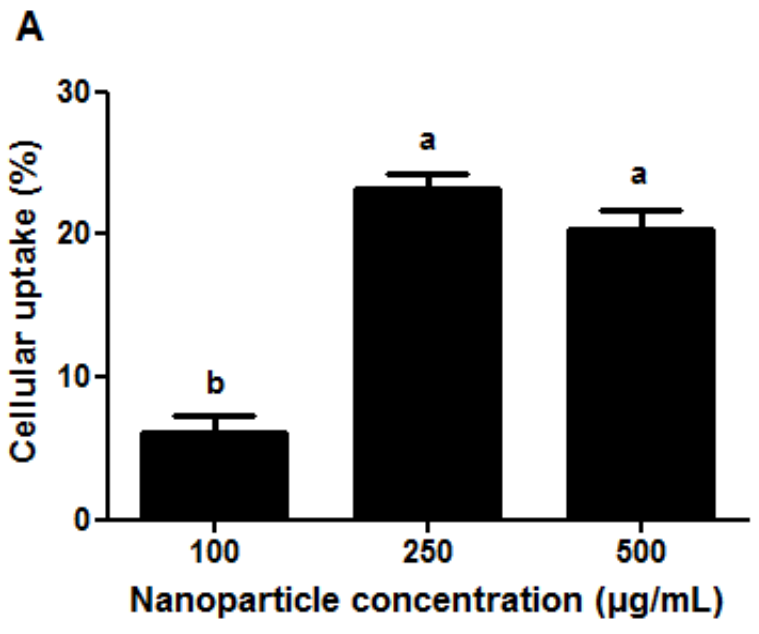

B

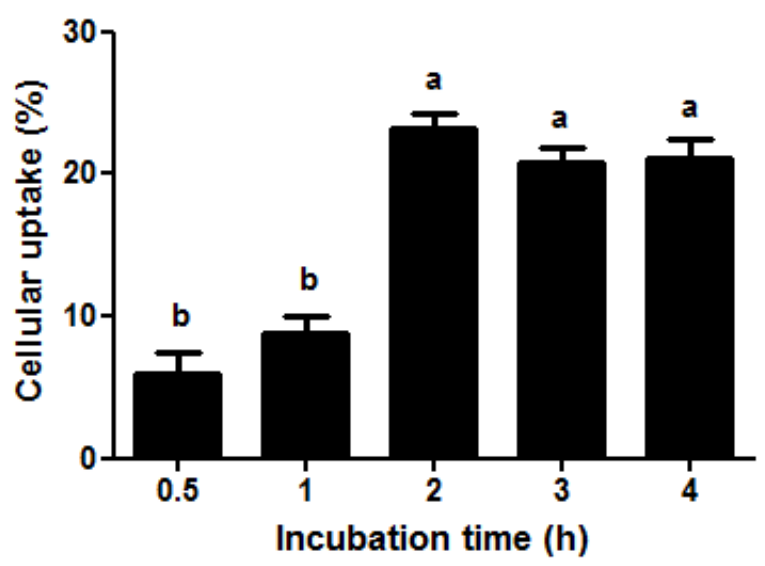

Figure 4. Effects of nanoparticle concentration and incubation time on the cellular uptake of $\beta$-lactoglobulin $(\beta-\lg )$ nanoparticles in Caco-2 cells. (A) Various concentration of fluorescein isothiocyanate (FITC)-conjugated $\beta$-lg nanoparticles (100, 250, and $500 \mu \mathrm{g} / \mathrm{mL}$ ) were added to Caco-2 cells and incubated at $37^{\circ} \mathrm{C}$ for $2 \mathrm{~h}$. (B) FITC-conjugated $\beta$-lg nanoparticles $(250 \mu \mathrm{g} / \mathrm{mL})$ were added to Caco- 2 cells and incubated at $37^{\circ} \mathrm{C}$ for $0,0.5,1,2,3,4 \mathrm{~h}$. Different letters on a column indicate significant differences $(\mathrm{p}<0.05)$.

no significant $(\mathrm{p}<0.05)$ differences in the cellular uptake of $\beta$ - $\lg$ nanoparticles after $2 \mathrm{~h}$ incubation were observed (Figure 4B). Therefore, FITC-conjugated $\beta$-lg nanoparticle suspensions with $250 \mu \mathrm{g} / \mathrm{mL}$ concentration and $2 \mathrm{~h}$ incubation time were used for further experiments.

It is believed that the cellular uptake of nanoparticles was affected by various morphological- and physicochemical properties of nanoparticles, such as their size and surface charge (Mansouri et al., 2006; Kumari and Yadav, 2011; Yoo et al., 2011). Effect of heating temperature on the cellular uptake of $\beta$-lg nanoparticles was displayed in Figure 5. A decrease in heating temperature from $70^{\circ} \mathrm{C}$ to $60^{\circ} \mathrm{C}$ led to a decrease in the size of $\beta$-lg nanoparticles from 192 to $98 \mathrm{~nm}$ (Figure 1). The cellular

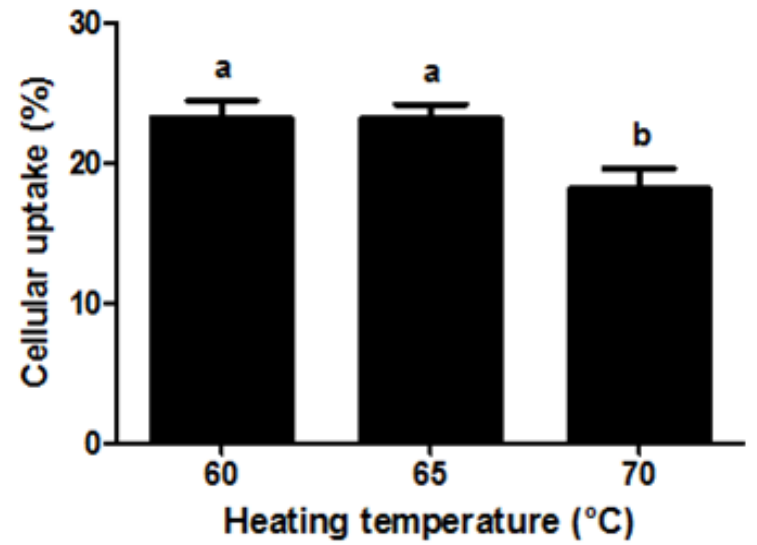

Figure 5. Effect of heating temperature on the cellular uptake of fluorescein isothiocyanate (FITC)-conjugated $\beta$-lactoglobulin $(\beta$ $\lg$ ) nanoparticles in Caco-2 cells. FITC-conjugated $\beta$-lg nanoparticles $(250 \mu \mathrm{g} / \mathrm{mL})$ were added to Caco-2 cells and incubated at $37^{\circ} \mathrm{C}$ for $2 \mathrm{~h}$. Different letters on a column indicate significant differences $(\mathrm{p}<0.05)$.

uptake of $\beta$-lg nanoparticles was significantly $(\mathrm{p}<0.05)$ increased as heating temperature decreased from $70^{\circ} \mathrm{C}$ to $60^{\circ} \mathrm{C}$ (Figure 5). Smaller $\beta$ - $\lg$ nanoparticles prepared at lower heating temperature had higher uptake efficiency of Caco- 2 cell compared to larger $\beta$-lg nanoparticles treated at higher heating temperature. There were significantly negative correlations between the particle size and the cellular uptake of $\beta$ - $\lg$ nanoparticles with $r$ values of -0.76 $(\mathrm{p}<0.001)$ (Table 1). Since nanoparticles with smaller size had larger surface areas available to adhere and interact with cell membranes, a decrease in the size of nanoparticles may lead to an increase in the interactions and binding with cell membranes, which can result in enhanced cellular uptake of nanoparticles (Win and Feng, 2005; Chen et al., 2006; Zhang et al., 2008; Kumari and Yadav, 2011; Iversen et al., 2011; Ha et al., 2013). Similar results were reported for oleyl chitosan and PLGA nanoparticles (Win and Feng, 2005; Zhang et al., 2008). The cellular uptake of oleyl chitosan nanoparticles was increased from $7.6 \%$ to $8.8 \%$ when the size of nanoparticle was decreased from 307 to $199 \mathrm{~nm}$ (Zhang et al., 2008). Win and Feng (2005) reported that a reduction in the size of PLGA nanoparticles from 1,000 to $100 \mathrm{~nm}$ resulted in an increase in the cellular uptake of nanoparticles from $9 \%$ to $14 \%$ in Caco- 2 cells.

On the other hand, an increase in the cellular uptake of $\beta$-lg nanoparticles was observed when $\beta$-lg nanoparticles treated at lower heating temperature had higher zeta-

Table 1. Pearson's correlation coefficients (r) between dependent variables

\begin{tabular}{lccc}
\hline & Particle size & Zeta-potential & Cellular uptake \\
\hline Particle size & & $-0.83^{* * *}$ & $-0.76^{* * *}$ \\
Zeta-potential & $-0.83^{* * *}$ & & $0.75^{* *}$ \\
Cellular uptake & $-0.76^{* * *}$ & $0.75^{* *}$ & \\
\hline$* * * *$ Signifi
\end{tabular}


potential value (surface charge) (Figure 5). Cellular uptake of $\beta$ - $\lg$ nanoparticles was positively correlated with zetapotential of $\beta-\lg$ nanoparticles $(r=0.75, \mathrm{p}<0.01)$ (Table 1$)$. Similar results was reported by $\mathrm{He}$ et al. (2010), who found that an increase in zeta-potential values of carboxymethyl chitosan grafted methyl methacrylate nanoparticles from -40 to $-15 \mathrm{mV}$ resulted in a significant increase in the cellular uptake of nanoparticles in murine macrophage cells. An increase in heating temperature may lead to an increase in the zeta-potential value of $\beta$-lg nanoparticles, which could result in stronger electrostatic repulsion between the $\beta$-lg nanoparticles and the cell membranes (He et al., 2010). This may cause a reduction in the adhesion and interaction of $\beta$-lg nanoparticles with Caco- 2 cell surface and hence a decrease in cellular uptake of nanoparticles.

\section{Cellular uptake of beta-lactoglobulin nanoparticles: Qualitative studies}

Qualitative study on the cellular uptake of FITC- conjugated $\beta$-lg nanoparticles were carried out using a CLSM. The cellular uptake of $\beta$-lg nanoparticles treated at various heating temperatures was shown in Figure 6. Propidium iodide (red fluorescence) was used to visualize the nuclei of Caco-2 cells while FITC (green fluorescence) was conjugated to $\beta$-lg to observe the cellular uptake of nanoparticles. Confocal microscopic images of Caco- 2 cells treated with FITC-conjugated $\beta$-lg nanoparticles were examined with PI channel (Figure 6, left panel), FITC channel (Figure 6, middle panel), and combined PI channel and FITC channel (Figure 6, right panel). The nuclei of Caco-2 cells were stained with PI (red) and displayed in Figure 6 (left panel). In Figure 6 (middle panel), the green color exhibited FITC-conjugated $\beta$-lg nanoparticles prepared at $60^{\circ} \mathrm{C}, 65^{\circ} \mathrm{C}$, or $70^{\circ} \mathrm{C}$ heating temperature. The overlaying images of Caco- 2 cell nuclei (PI, red) and $\beta-1 g$ nanoparticles (FITC, green) were shown in Figure 6 (right panel). In Figure 6 (right panel), $\beta$-lg nanoparticles were observed around the nuclei of Caco- 2 cells (in the cell

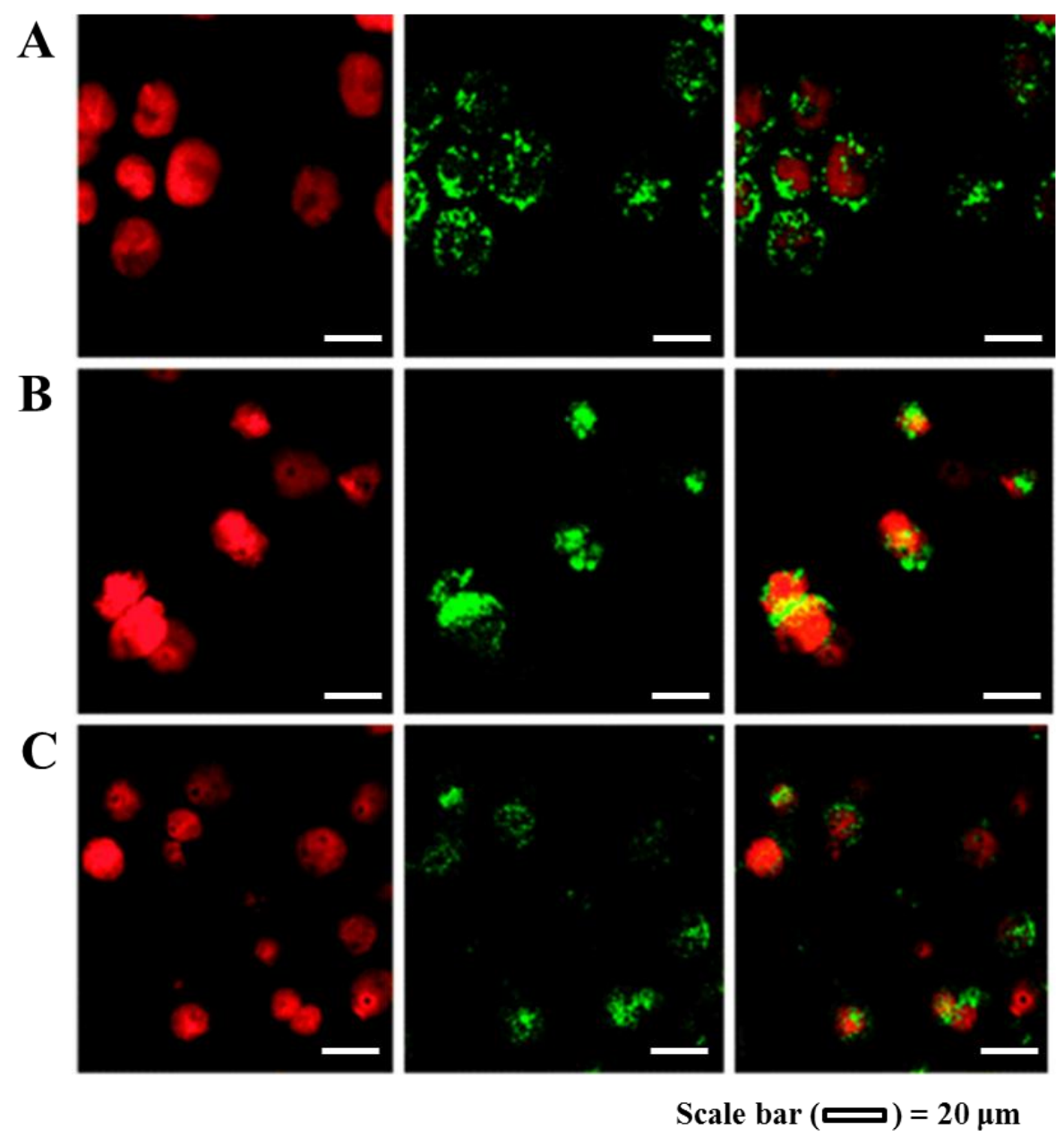

Figure 6. Confocal laser scanning microscopy images of Caco- 2 cells after $2 \mathrm{~h}$ incubation at $37^{\circ} \mathrm{C}$ with fluorescein isothiocyanate (FITC)-conjugated $\beta$-lactoglobulin $(\beta-\mathrm{lg})$ nanoparticles $(250 \mu \mathrm{g} / \mathrm{mL})$ prepared at $(\mathrm{A}) 60^{\circ} \mathrm{C}$, (B) $65^{\circ} \mathrm{C}$, and $(\mathrm{C}) 70^{\circ} \mathrm{C}$ heating temperatures. To observe the cellular uptake of $\beta$-lg nanoparticles, cells were stained with propidium iodide (PI) and FITC-conjugated $\beta$-lg nanoparticles were used. Cellular uptake of FITC-conjugated $\beta$-lg nanoparticles was imaged by PI channel (left panel), FITC channel (middle panel), and combined PI channel and FITC channel (right panel), respectively. 
membrane and inside the cytosol) indicating that $\beta$-lg nanoparticles were successfully taken up by Caco- 2 cells. No fluorescence was observed in the confocal microscopic image of control cells (data not shown) indicating that Caco- 2 cell or $\beta$-lg do not have autofluorescence.

In conclusion, food-grade $\beta$-lg nanoparticles with various particle size and surface charge were successfully manufactured by the internal gelation method. The $\beta$-lg nanoparticles were non-cytotoxic to Caco-2 cells and can be taken up by Caco-2 cells. Heating temperature can modulate the size and surface charge of $\beta$-lg nanoparticles. The size and surface charge of $\beta$-lg nanoparticles were crucial factors affecting the cellular uptake of $\beta$-lg nanoparticles in Caco- 2 cells. A better understanding of the factors contributing to the cellular uptake of nanoparticles could allow dairy processors to apply $\beta$-lg nanoparticlesas a delivery system in functional foods.

\section{ACKNOWLEDGMENTS}

This research was carried out with the support of "Cooperative Research Program for Agriculture Science \& Technology Development (PJ009659032013)" Rural Development Administration and Basic Science Research Program through the National Research Foundation of Korea (NRF) funded by the Ministry of Education, Science and Technology (2011-0013978; 2012R1A1A4A01013793), Republic of Korea.

\section{REFERENCES}

Chen, L. and M. Subirade. 2005. Chitosan/ $\beta$-lactoglobulin coreshell nanoparticles as nutraceutical carriers. Biomaterials 26:6041-6053.

Chen, L., G. E. Remondetto, and M. Subirade. 2006. Food proteinbased materials as nutraceutical delivery systems. Trends Food Sci. Technol. 17:272-283.

Cho, E. C., J. Xie, P. A. Wurm, and Y. Xia. 2009. Understanding the role of surface charges in cellular adsorption versus internalization by selectively removing gold nanoparticles on the cell surface with a $I_{2} / K I$ etchant. Nano Lett. 9:1080-1084.

Cockburn, A., R. Bradford, N. Buck, A. Constable, G. Edwards, B. Haber, P. Hepburn, J. Howlett, F. Kampers, C. Klein, M. Radomski, H. Stamm, S. Wijnhoven, and T. Wildemann. 2012. Approaches to the safety assessment of engineered nanomaterials (ENM) in food. Food Chem. Toxicol. 50:22242242.

Ha, H. K., J. W. Kim, M.-R. Lee, and W.-J. Lee. 2013. Formation and characterization of quercetin-loaded chitosan oligosaccharide/ $\beta$-lactogloublin nanoparticle. Food Res. Int. 52:82-90.

He, C., Y. Hu, L. Yin, C. Tang, and C. Yin. 2010. Effects of particle size and surface charge on cellular uptake and biodistribution of polymeric nanoparticles. Biomaterials 31:3657-3666.
Hu, B., Y. Ting, X. Zeng, and Q. Huang. 2012. Cellular uptake and cytotoxicity of chitosan-caseinophosphopeptides nanocomplexes loaded with epigallocatechin gallate. Carbohydr. Polym. 89:362-370.

Iversen T. G., T. Skotland, and K. Sandvig. 2011. Endocytosis and intracellular transport of nanoparticles: Present knowledge and need for future studies. Nano Today 6:176-185.

Kumari, A. and S. K. Yadav. 2011. Cellular interactions of therapeutically delivered nanoparticles. Expert Opin. Drug Deliv. 8:141-151.

Lee, M. R., G.-W. Nam, H.-N. Choi, H.-S. Yun, S.-H. Kim, S.-K. You, D.-J. Park, and W.-J. Lee. 2008. Structure and chemical properties of beta-lactoglobulin nanoparticles. J. Agric. Life Sci. 42:31-36.

Lee, M. R., H.-N. Choi, H.-K. Ha, and W.-J. Lee. 2013. Production and characterization of beta-lactoglobulin/alginate nanoemulsion containing coenzyme $\mathrm{Q}_{10}$ : Impact of heat treatment and alginate concentrate. Korean J. Food Sci. Anim. 33:67-74.

Livney, Y. D. 2010. Milk proteins as vehicles for bioactives. Curr. Opin. Colloid. Interface Sci. 15:73-83.

Mansouri, S., Y. Cuie, F. Winnik, Q. Shi, P. Lavigne, M. Benderdour, E. Beaumont, and J. C. Fernandes. 2006. Characterization of folate-chitosan-DNA nanoparticles for gene therapy. Biomaterials 27:2060-2065.

Napierska, D., L. C. J. Thomassen, V. Rabolli, D. Lison, L. Gonzalez, M. Kirsch-Volders, J. A. Martens, and P. H. Hoet. 2009. Size-dependent cytotoxicity of monodisperse silica nanoparticles in human endothelial cells. Small 5:846-853.

Powell, J. J., N. Faria, E. Thomas-McKay, and L. C. Pele. 2010. Origin and fate of dietary nanoparticles and microparticles in the gastrointestinal tract. J. Autoimmun. 34:J226-J233.

Pushpanathan, M., J. Rajendhran, S. Jayashree, B. Sundarakrishnan, S. Jayachandran, and P. Gunasekaran. 2012. Direct cell penetration of the antifungal peptide, MMGP1, in Canadida albicans. J. Pept. Sci. 18:657-660.

Russell, P., D. Hewish, T. Carter, K. Sterling-Levis, K. Ow, M. Hattarki, L. Doughty, R. Guthrie, D. Shapira, P. L. Molloy, J. A. Werkmeister, and A. A. Kortt. 2004. Cytotoxic properties of immunoconjugates containing melittin-like peptide 101 against prostate cancer: in vitro and in vivo studies. Cancer Immunol. Immunother. 53:411-421.

SAS Institute Inc. 2003. SAS User's Guide: version 9.1, Cary, NC, USA.

Schmitt, C., C. Bovay, A. M. Vuilliomenet, M. Rouvet, L. Bovetto, R. Barbar, and C. Sanchez. 2009. Multiscale characterization of individualized $\beta$-lactoglobulin microgels formed upon heat treatment under narrow $\mathrm{pH}$ range conditions. Langmuir 25:7899-7909.

Verma, A. and F. Stellacci. 2010. Effect of surface properties on nanoparticle-cell interactions. Small 6:12-21.

Win, K. Y. and S.-S. Feng. 2005. Effects of particle size and surface coating on cellular uptake of polymeric nanoparticles for oral delivery of anticancer drugs. Biomaterials 26:27132722.

Yin, H., H. P. Too, and G. M. Chow. 2005. The effects of particle size and surface coating on the cytotoxicity of nickel ferrite. Biomaterials. 26:5818-5826.

Yoo, J. W., N. Doshi, and S. Mitragotri. 2011. Adaptive micro and 
nanoparticles: Temporal control over carrier properties to facilitate drug delivery. Adv. Drug Deliv. Rev. 63:1247-1256.

Zhang, J., X. G. Chen, W. B. Peng, and C. S. Liu. 2008. Uptake of oleoyl-chitosan nanoparticles by A549 cells. Nanomedicine 4:208-214.
Zimet, P. and Y. D. Livney. 2009. Beta-lactoglobulin and its nanocomplexes with pectin as vehicles for $\omega-3$ polyunsaturated fatty acids. Food Hydrocoll. 23:1120-1126. 